Research Article

\title{
Escitalopram reduces severity of depression and improves quality of life in patients with chronic obstructive pulmonary disease in an open label parallel group study
}

\author{
Lakshmi Rajesh Channareddy ${ }^{1}$, Eshwar Reddy Ravula ${ }^{2}$, Vignan Kumar G. P. ${ }^{3 *}$
}

\author{
${ }^{1}$ Department of Psychiatry \\ ASRAM Medical College \\ Eluru-534004, Andhra Pradesh, \\ India, \\ ${ }^{2}$ Department of Psychiatry \\ Narayana Medical College \\ Nellore-524002, Andhra \\ Pradesh, India, \\ ${ }^{3}$ Department of Pulmonology, \\ Narayana Medical College \\ Nellore-524002, Andhra \\ Pradesh, India
}

Received: 16 February 2016

Accepted: 23 February 2016

\section{*Correspondence to:}

Dr. Vignan Kumar G. P.,

Email: pill4ill@yahoo.co.in

Copyright: (C) the author(s), publisher and licensee Medip Academy. This is an openaccess article distributed under the terms of the Creative Commons Attribution NonCommercial License, which permits unrestricted noncommercial use, distribution, and reproduction in any medium, provided the original work is properly cited.

\begin{abstract}
Background: Chronic obstructive pulmonary disease (COPD) is characterised by progressive and persistent airflow limitation with frequent exacerbations and hospitalizations contributing to overall morbidity and mortality. We evaluated the efficacy of antidepressant escitalopram therapy in depressed individuals suffering from chronic obstructive pulmonary disease.

Methods: The sample comprised of sixty patients. Thirty patients received antidepressant escitalopram, while the remaining half served as controls. Hamilton depression rating and WHO-BREF questionnaire were the tools to assess severity of depression and quality of life. The severity of COPD was recorded using spirometry (FEV1\%). Clinical assessments were at baseline and at week- 2 and week- 8 of follow up in both intervention and control groups.

Results: It was found that both the groups were similar on the severity of the illness (COPD) at entry. FEV $1 \%$ of both the groups showed similar improvement after 8 weeks. Treatment with escitalopram showed a significant decrease in the severity of depression score and improvement on all the domains of quality of life when compared with the baseline. After the intervention, it was found that the HAM-D scores in the experimental group decreased from 24.44 to 17.50 while in the control group, it was from 20.11 to 19.67 . The magnitude of improvement was significantly higher with intervention compared to controls.

Conclusions: Escitalopram reduces severity of depression and improves quality of life which was independent of improvement in FEV1. It could be asserted that this antidepressant improved the patient's mood, fatigue and helplessness, which could have improved the quality of life of these patients.
\end{abstract}

Keywords: Chronic obstructive pulmonary disease, Depression, Quality of life, Hamilton depression rating scale, FEV1

\section{INTRODUCTION}

Chronic obstructive pulmonary disease (COPD) is characterised by progressive and persistent airflow limitation with frequent exacerbations and hospitalizations contributing to overall morbidity and mortality. ${ }^{1}$ Depression a common mental disorder is present in up to $60 \%$ of patients with chronic obstructive pulmonary disease (COPD). ${ }^{2}$ Severity of COPD (FEV $1 \%$ $<50)$ has been associated with increased number of exacerbations and hospitalizations which in turn have been responsible for increase in depressive symptoms and low quality of life. Depressed patients may have lower self-confidence and a feeling of hopelessness. They may have suboptimal disease control due to poor self-care strategies and adherence to medications. Clinical observations suggest that mood disorders increase dyspnoea and impede pulmonary rehabilitation in COPD. ${ }^{2-6}$ Studies have also shown that depression has been associated with low quality of life. In Chronic illness where depression is comorbidity, quality of life tends to be much lower. Cully et al $^{7}$ examined the relative contribution of clinical depression and/or anxiety to their quality of life in patients with chronic obstructive 
pulmonary disease (COPD) and found that both depression and anxiety were significantly related to negative quality-of-life outcomes. Therefore it is important to evaluate both the antidepressant responsiveness of depression in COPD and the impact of treatment on patient's functional capacity and quality of life. To this purpose we evaluated the effect of antidepressant therapy with escitalopram in half of these depressed individuals, while the remaining half served as controls.

\section{METHODS}

This quasi experimental study comprised of COPD patients, attending the outpatient department of pulmonology at Narayana Medical College, Nellore. Study participants were both male and female patients, between 20-60 years, fulfilling the GOLD criteria for severe COPD and having HAM-D score $>20$ and willing to provide informed consent for participation. Patients with mental retardation or any other psychiatric conditions except depression or those who were receiving antidepressant therapy were excluded. At entry, all patients underwent assessments for forced expiratory volume in one second (FEV1) using spirometry, severity of depression using Hamilton depression rating scale (HAM-D) and quality of life by world health organisation quality of life questionnaire-BREF version which assesses four major domains of QOL such as physical, psychological, social and environment. A score of 0-7 on HAM-D is considered to be normal; scores of 20 or higher indicate moderately severe depression. Sixty patients were screened, out of them, 41 met the criteria for study entry and assigned to one of the two groups. Group-1 received antidepressant therapy with either 10 or $20 \mathrm{mg}$ of Escitalopram along with the standard treatment for COPD and group-2 received standard treatment for COPD alone. These patients were re-evaluated for assessments of their pulmonary function, severity of depression and quality of life at the end of week- 2 and week-8 weeks using the same tools. Five patients dropped out during the follow up phase of the study, leaving 18 participants in each group. The reason for dropout was not available and this data drop-outs into final analysis.

\section{Statistical analysis}

Descriptive statistics were mean, standard deviation, actual numbers and percentages. Independent sample $t$ test and paired sample $t$ test were used to compare variables between two groups. The data was analysed using Statistical Package for Social Sciences version (SPSS version 20.0). Sample size was calculated on the anticipated SD of 4.5 each group (assume equal) alpha $=0.05$, two-tailed with $80 \%$ power to detect a five point difference in HAM-D score as compared with baseline. A total of 16 subjects were required to demonstrate antidepressant activity, additionally $30 \%$ were added for data losses and drop outs. So a total of 21 per group subjects were required for conduct of this study. Recruitment was achieved in experimental group. However data for final analysis included 18 subjects.

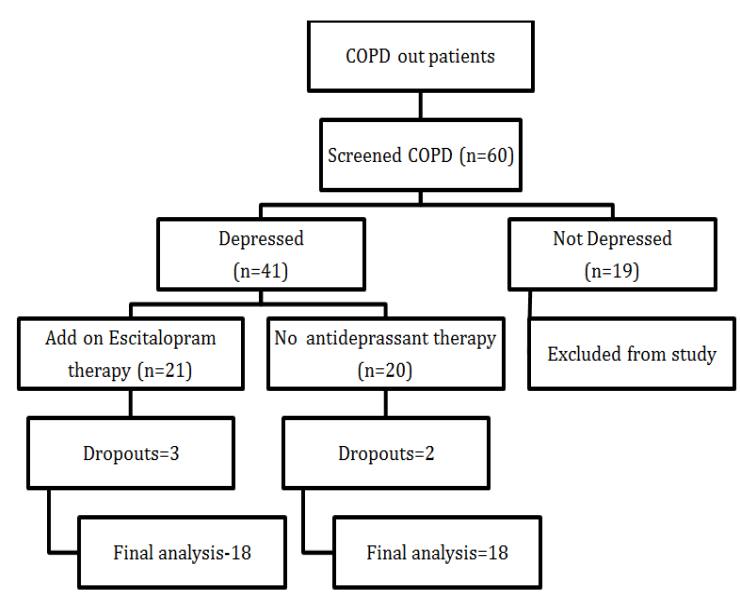

Figure 1: Patient participation.

\section{RESULTS}

A total of 60 patients were evaluated, out of them $73.3 \%$ patients were above 50 years of age while $26.7 \%$ were below 50 years of age. The mean age of the sample studied was found to be $53 \pm 6$ years. The prevalence of depression in our study was $68.3 \%$. It can be seen from table 1 , that both the groups were similar on the severity of the illness (COPD) at entry and showed similar improvement in FEV1\% after 8 weeks (Figure 2). The mean drop in HAM-D scores was from 24.44 to 17.50 after treatment with escitalopram where as in the control group it marginally decreased from 20.11 to 19.67 . The magnitude of reduction in HAM-D scores in antidepressant group was statistically significant as compared to the control group $(\mathrm{p}<0.05)$ (Figure 3$)$. When we analysed the individual domains score and total score of quality of life, we found that there was a trivial increase in physical, social and environmental domains and a marginal drop off in the psychological quality of life of patients in the control group. However, in the experimental group, we observed a significant increase in all the domains. Though homogeneity of the groups was not maintained at the start of the study there was a significant improvement in the experimental group at the end of eight weeks in both the depressive symptoms and quality of life when compared to insignificant increase control group. Treatment with antidepressant showed a significant fall in HAM-D scores and improvement in QOL at 8 weeks independent of improvement in pulmonary function. Significant improvement was observed in QOL-total in the interventional group where as it remained unchanged in control group after 8 weeks (Figure 4). 
Table 1: Comparison of pulmonary function, depression score and quality of life of patients with COPD.

\begin{tabular}{|llllll|}
\hline \multicolumn{7}{l}{$\begin{array}{l}\text { Control } \\
\text { Paramet } \\
\text { ers }\end{array}$} & $\begin{array}{l}\text { Interventional group } \\
\text { Mean }\end{array}$ & SD & Mean & SD & $\begin{array}{l}\text { Signifi } \\
\text { cance }\end{array}$ \\
\hline FEV1\% & & & & & \\
\hline Baseline & 44.06 & 5.09 & 41.44 & 6.80 & $\mathrm{P}>0.05$ \\
\hline 2 weeks & 43.78 & 4.87 & 41.44 & 6.80 & $\mathrm{P}>0.05$ \\
\hline 8weeks & 45.50 & 5.02 & 43.89 & 6.62 & $\mathrm{P}>0.05$ \\
\hline HAM-D & & & & & \\
\hline Baseline & 20.11 & 3.19 & 24.44 & 5.10 & $\mathrm{P}<0.05$ \\
\hline 2 weeks & 19.78 & 3.23 & 23.22 & 4.78 & $\mathrm{P}<0.05$ \\
\hline 8weeks & 19.67 & 4.04 & 17.50 & 4.89 & $\mathrm{P}>0.05$ \\
\hline QOL Physical & & & & \\
\hline Baseline & 42.67 & 5.27 & 38.33 & 7.48 & $\mathrm{P}<0.05$ \\
\hline 2 weeks & 44.39 & 6.50 & 39.72 & 7.18 & $\mathrm{P}<0.05$ \\
\hline 8weeks & 44.28 & 7.61 & 45.39 & 7.71 & $\mathrm{P}>0.05$ \\
\hline QOL Psychological & & & \\
\hline Baseline & 49.39 & 5.91 & 43.17 & 7.09 & $\mathrm{P}<0.05$ \\
\hline 2 weeks & 47.72 & 6.02 & 45.28 & 6.81 & $\mathrm{P}>0.05$ \\
\hline 8weeks & 49.06 & 6.71 & 57.22 & 10.71 & $\mathrm{P}<0.05$ \\
\hline QOL Social & & & & \\
\hline Baseline & 44.17 & 6.99 & 37.39 & 10.34 & $\mathrm{P}<0.05$ \\
\hline 2 weeks & 44.94 & 5.68 & 37.72 & 10.01 & $\mathrm{P}<0.05$ \\
\hline 8 weeks & 44.61 & 7.16 & 43.78 & 9.92 & $\mathrm{P}>0.05$ \\
\hline QOL Environmental & & & \\
\hline Baseline & 46.06 & 7.26 & 42.44 & 8.18 & $\mathrm{P}>0.05$ \\
\hline 2 weeks & 45.39 & 7.14 & 43.11 & 8.02 & $\mathrm{P}>0.05$ \\
\hline 8 weeks 46.39 & 6.70 & 47.72 & 6.99 & $\mathrm{P}>0.05$ \\
\hline QOL Total & & & & \\
\hline Baseline & 45.50 & 5.38 & 40.33 & 7.27 & $\mathrm{P}<0.05$ \\
\hline 2 weeks & 45.79 & 5.41 & 41.18 & 7.07 & $\mathrm{P}<0.05$ \\
\hline 8 weeks & 46.07 & 6.40 & 48.44 & 8.18 & $\mathrm{P}>0.05$ \\
\hline
\end{tabular}

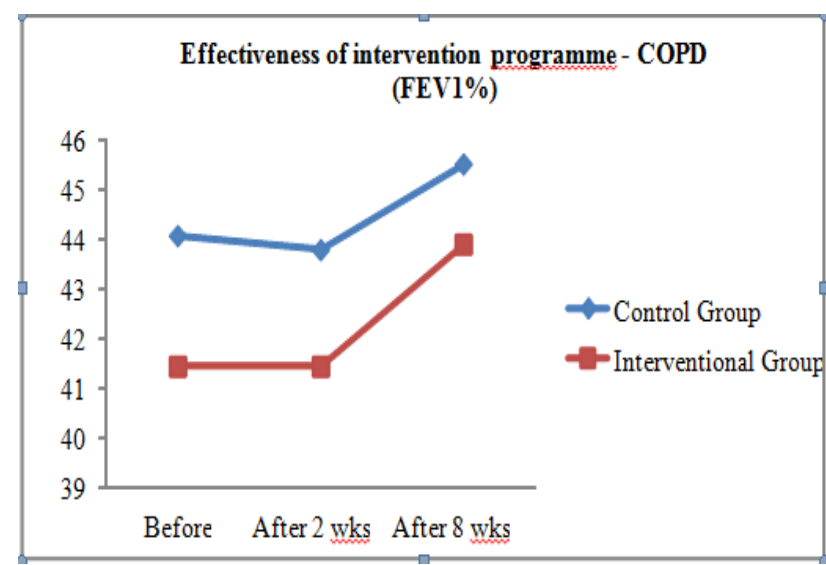

Figure 2: Comparison between FEV1\% of control and interventional group.

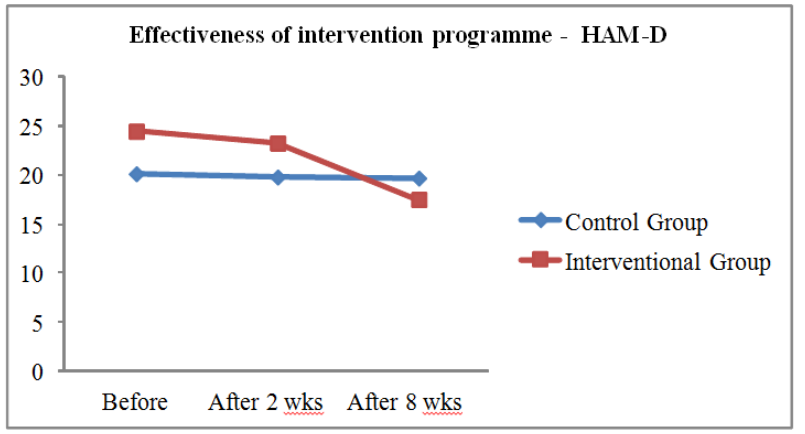

Figure 3: Comparison between HAM-D scores of control and interventional group.

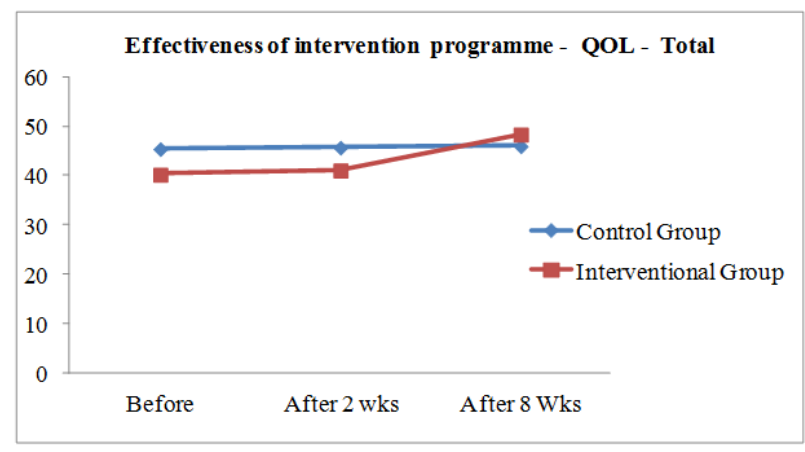

Figure 4: Comparison between QOL -total of control and interventional group.

\section{DISCUSSION}

The aim of the study was to assess the prevalence of depression in individuals suffering with severe and very severe COPD and to assess the acute effectiveness of addon antidepressant therapy. The present study results show that the prevalence of depression is significantly high in patients suffering with COPD which considerably influences the quality of life. Treatment with antidepressant escitalopram is effective in reducing the severity of depressive symptoms and improving the quality of life in patients suffering from Chronic Obstructive Pulmonary Disease (COPD). The margin of decrease in the severity of depression was found to be significant for the experimental group as compared to the control group. The decrease is attributed to the use of add on anti-depressant therapy in the experimental group. These results are in congruence with a randomized double blind parallel group trial comparing paroxetine versus placebo. ${ }^{8}$ It could be asserted that as the anti-depressants improved the patient's low mood, fatigue and helplessness, and quality of life of these patients.

It is also pertinent that while the psychological domain of quality of life in patients in the control group deteriorated, the same domain saw a significant increase in the experimental group in which anti-depressants were added to the treatment as usual. These results are consistent with the findings of a randomized double blind parallel group's trial comparing nortriptyline versus placebo for 12 
weeks. ${ }^{9}$ However, this study reported that physiological measures remained unaffected even in the treatment group. In the current study also, no significant improvement was found in the FEV\% in the experimental group as compared to the control group thus indicating that the improvement in depressive symptom, quality of life and the outcome of the illness was not mediated through the physiological change. Though homogeneity of the groups was not maintained at the start of the study there was a significant improvement in the experimental group at the end of eight weeks in both the depressive symptoms and quality of life when compared to the control group where the improvement was insignificant when results were analysed using paired sample " $\mathrm{t}$ " test. These results are consistent with a review done by Fritzsche et $\mathrm{al}^{10}$ where the authors found that both antidepressants and cognitive behaviour therapy could lead to significant functional improvements in patients suffering from COPD.

\section{Limitations of the study}

This study includes less number of patients and shorter duration of treatment. Experimental design is not a randomized and blinded. Due to ethical considerations severely depressed patients were not assigned to the control group.

\section{CONCLUSION}

The prevalence rates of depression among COPD patients were as high as $68.3 \%$. There was a positive correlation between the number of hospitalizations and exacerbations to the severity of depression. Quality of life in COPD patients with depression as co-morbidity was found to be poor in all the four domains namely physical, psychological, social and environmental when compared to those having only COPD as an illness. The severity of COPD was positively correlated with severity of depression and showed a negative correlation with the quality of life. Following the intervention, there was significant decrease in the scores of depression on the HAM-D scale and improvement in quality of life in the interventional group when compared to that of the control group.

Funding: No funding sources Conflict of interest: None declared

Ethical approval: The study was approved by the Institutional Ethics Committee

\section{REFERENCES}

1. Fabbri L, Hurd S. Global strategy for the diagnosis, management and prevention of COPD: 2003 update. European Respir J. 2003;22(1):1-2.

2. $\mathrm{Xu} \mathrm{W,} \mathrm{Collet} \mathrm{J-P,} \mathrm{Shapiro} \mathrm{S,} \mathrm{Lin} \mathrm{Y,} \mathrm{Yang} \mathrm{T,} \mathrm{Platt}$ RW et al. Independent effect of depression and anxiety on chronic obstructive pulmonary disease exacerbations and hospitalizations. American $\mathbf{J}$ Respir Crit Care Med. 2008;178(9):913-20.

3. Jain A, Lolak S. Psychiatric aspects of chronic lung disease. Curr Psych Reports. 2009;11(3):219-25.

4. Janssen DJ, Spruit MA, Leue C, Gijsen C, Hameleers $\mathrm{H}$, Schols JM et al. Symptoms of anxiety and depression in COPD patients entering pulmonary rehabilitation. Chronic Respir Dis. 2010;7(3):147-57.

5. Jennings JH, DiGiovine B, Obeid D, Frank C. The association between depressive symptoms and acute exacerbations of COPD. Lung. 2009;187(2):128-35.

6. Regvat J, Žmitek A, Vegnuti M, Košnik M, Šuškovič S. Anxiety and depression during hospital treatment of exacerbation of chronic obstructive pulmonary disease. J Intern Med Res. 2011;39(3):1028-38.

7. Cully JA, Graham DP, Stanley MA, Ferguson CJ, Sharafkhaneh A, Souchek J et al. Quality of life in patients with chronic obstructive pulmonary disease and comorbid anxiety or depression. Psychosomatics. 2006;47(4):312-9.

8. Lacasse Y, Beaudoin L, Rousseau L, Maltais F. Randomized trial of paroxetine in end-stage COPD. Monaldi archives for chest disease $=$ Archivio Monaldi per le malattie del torace/Fondazione clinica del lavoro, IRCCS [and] Istituto di clinica tisiologica e malattie apparato respiratorio, Universita di Napoli, Secondo ateneo. 2003;61(3):140-7.

9. Borson S, McDonald GJ, Gayle T, Deffebach M, Lakshminarayan S, VanTuinen C. Improvement in mood, physical symptoms, and function with nortriptyline for depression in patients with chronic obstructive pulmonary disease. Psychosomatics. 1992;33(2):190-201.

10. Fritzsche A, Clamor A, von Leupoldt A. Effects of medical and psychological treatment of depression in patients with COPD- a review. Respir Med. 2011;105(10):1422-33.

Cite this article as: Channareddy LR, Ravula ER, Kumar VGP. Escitalopram reduces severity of depression and improves quality of life in patients with chronic obstructive pulmonary disease in an open label parallel group study. Int J Basic Clin Pharmacol 2016;5:281-4. 